Research Article

\title{
Stress Relief and Support for Stability of Deep Mining Roadway with Thick Top Coal in Hujiahe Coal Mine with the Risk of Rock Burst
}

\author{
Wenjing Liu, ${ }^{1,2}$ Deyu Qian $\mathbb{D}^{\mathbb{D}},{ }^{3}$ Xingguo Yang $\mathbb{D},{ }^{3}$ Sujian Wang, ${ }^{2,4,5}$ Jinping Deng, ${ }^{3}$ Qi Cui, ${ }^{3}$ \\ and Zexiang $\mathbf{L i}^{3}$ \\ ${ }^{1}$ School of Energy Engineering, Xi'an University of Science and Technology, Xi'an 710054, Shaanxi, China \\ ${ }^{2}$ Shaanxi Coal Industry and Chemical Technology Research Institute Co., Ltd, Xi'an, 710100, Shaanxi, China \\ ${ }^{3}$ School of Mines, China University of Mining and Technology, Xuzhou 221116, China \\ ${ }^{4}$ The National Joint Engineering Research Center of the Green, Safe and Efficient Coal Mining, Xi'an 710065, China \\ ${ }^{5}$ Sanqin Scholar Innovation Team, Shaanxi Coal Industry Chemical Group Company Limited, Xi'an 710100, China
}

Correspondence should be addressed to Deyu Qian; qian@cumt.edu.cn and Xingguo Yang; ts20020065a31@cumt.edu.cn

Received 16 April 2021; Revised 7 June 2021; Accepted 6 August 2021; Published 31 August 2021

Academic Editor: Pengfei Wang

Copyright ( $\odot 2021$ Wenjing Liu et al. This is an open access article distributed under the Creative Commons Attribution License, which permits unrestricted use, distribution, and reproduction in any medium, provided the original work is properly cited.

Rock burst is a typical dynamic disaster in deep underground coal mining. Based on the support problems of the deep roadways in fully mechanized caving face 401111 of Hujiahe Coal Mine suffering from rock burst in Shaanxi Province of China, the failure law and influencing factors of the surrounding rock of the roadway are analyzed. The results show that the deformation of surrounding rock in the roadway shows the characteristics of elastic, plastic transformation, rheology, and expansion. At the same time, it has the typical characteristics of deep roadway, such as the fast deformation speed, long duration, asymmetric deformation, and large loose broken area of surrounding rock. Based on the principle of "strengthening support in shallow zones" and "deep pressure relief in deep zones" in the surrounding rock, the control scheme of surrounding rock in the return roadway of fully mechanized caving working face 401111 is proposed by taking the large diameter pressure relief and deep hole blasting as the main means of pressure relief. The practice shows that the surrounding rock of the return roadway is relatively stable after the implementation of the new scheme, which shows that the design of the new support scheme is reasonable and reliable. It is of great significance for the stability control of surrounding rock of the mining roadway suffering from rock burst.

\section{Introduction}

Rock burst is a typical dynamic disaster in deep underground coal mining. At present, with China's coal mining gradually entering the peak period of deep mining and the popularization of rapid tunneling technology, the frequency and intensity of rock burst are also increasing. Rock burst is a geological phenomenon that the deformation energy in coal and rock mass is released rapidly in a short time, accompanied by the throwing of coal and rock mass, huge sound, and vibration. The occurrence conditions and mechanism of rock burst involve multifield and multilevel complex theory, and there are many influencing factors. The effectiveness of prediction and prevention of rock burst needs to be improved. So far it has not formed a complete system of rock burst measurement, prediction, and treatment [1-4].

In terms of rock burst control, under the selection of reasonable mining development and deployment, coal mining methods, and technical measures, it is mainly from two aspects of active disaster relief and strengthening support. The methods of active crisis relief include blasting pressure relief, high-pressure water injection of coal seam, roof cutting pressure relief, and large-diameter borehole pressure relief. Among them, large-diameter borehole pressure relief has become the most effective and widely used method of pressure relief and crisis relief in the world due to 
its outstanding advantages such as simple process, small engineering quantity, low cost, strong adaptability, obvious effect, and small influence on production [5-7].

A lot of research has been conducted on the application of pressure relief theory and measures in different geological conditions. Zhang et al. [8] proposed the specific force field conditions and trigger stress values of rock burst on the basis of numerical simulation and theoretical calculation. Wang et al. [9] studied the stress distribution characteristics of narrow coal pillar goaf and proposed the rock burst prevention technology of gob-side entry driving. Zhao et al. [10] studied the relationship between rock burst and geological characteristics, described in detail the spatiotemporal characteristics of rock burst, studied the geological characteristics of rock burst, and analyzed the possible causes of rock burst. Zuo et al. [11] proposed a comprehensive rock burst research method involving three elements of Newton's second law and the feasible research direction of rock burst. Zhu et al. [12] used the triaxial rock burst system to study the influence of the hyperstress state on rock burst in deep underground coal mining. The results show that, under different loading and unloading stress paths, the soil has obvious time lag effect. Under constant confining pressure, when the axial stress is three times greater than the uniaxial compressive strength of the coal sample, the coal sample is subjected to impact failure. Fu et al. [13] established the instability analysis model of deep goaf, analyzed the stress path characteristics of surrounding rock in the process of goaf formation, introduced the local energy release rate index (LERR) to analyze the energy evolution law, and established the energy criterion of surrounding rock instability. Chen et al. [14] studied the characteristics, size, law of the radiation energy of rock burst, and relationship between radiation energy and intensity. On this basis, taking energy as the evaluation index of rock burst strength classification, a new quantitative classification method of rock burst strength using hierarchical clustering technology and full linkage method is proposed. Yang et al. [15] studied the deformation failure mechanism and spectrum characteristics of low-frequency strong dynamic disturbance. The results show that, with the increase of roof pressure, the load of roof and two sides first increases, then decreases, and tends to be stable. After the dynamic disturbance, the acceleration waveform of the measuring point of the roadway surrounding rock lasted about $0-0.05 \mathrm{~s}$, and the attenuation was fast. The tail wave was developed. The frequency range of the disturbance wave was wide, and the amplitude was large, which was mainly manifested as more high-frequency components. Aiming at the surrounding rock control problem of gob-side entry retaining under typical roof conditions, $\mathrm{Wu}$ et al. [16] systematically analyzed the serious damage area, degree and scope of damage, and the dynamic evolution process of surrounding rock of gob-side entry retaining under four typical roof conditions. The law of extension and evolution of the plastic zone of surrounding rock is expounded. Wang et al. [17] outlined the evolution mechanism of two different types of rock bursts and proposed measures such as caving mining, deep hole blasting, and large diameter drilling, which provided a basis for the risk control of rock burst disasters in subsequent mining activities. He et al. [18] studied the mechanism of rock burst in steeply inclined extrathick coal seam and optimized the pressure relief measures by comparing the pressure relief effects of three stress blasting schemes. Cui et al. [19] used a physical similar material simulation experiment and acoustic emission monitoring method to study overburden failure law and acoustic emission characteristics in the coal mining process. It was considered that hard roof of working face and stress concentration caused by multiple mining were the main control factors of rock burst in this area. Cui et al. [20] studied the evolution law of overburden failure angle and roof pressure relief technology under repeated mining and verified the rationality and reliability of the theoretical formula for the fracture angle of single coal seam and double coal seam and double key strata. Kong et al. [21] used the three-dimensional continuum fast Lagrangian analysis (FLAC3D) software to study the deformation and rock burst potential of roadway under different dynamic and static loads. The results show that, under the same static load conditions, the greater the dynamic load, the greater the roadway deformation increment; the roadway under high static load is more prone to deformation and instability under dynamic load. Under different static load conditions, the dynamic response of roadway supporting stress distribution is different. Wei et al. [22] summarized the optimal layout method and mitigation strategy, including the latest ground support technology and pressure relief technology, and proposed the rock burst management framework, including three key stages of rock burst profile identification, rock burst management scheme formulation, and rock burst management. Guo et al. [23] found that blasting disturbance had an important influence on the strength and scale of rock burst and proposed to follow two criteria in rock burst control. One is to alleviate the high stress concentration, and the other is to control the disturbance stress. Zhou et al. [24] used the entropy weight cloud model to predict rock burst classification and sorted the sensitivity of the main influencing factors of rock burst. However, the research on the synergistic effect of borehole pressure relief and anchoring is insufficient. Therefore, further in-depth study on the synergistic mechanism of pressure relief and anchoring has important practical significance for improving the theory of rock burst control, guiding the prevention and control of rock burst, and reducing the occurrence of coal mine dynamic disaster accidents. Taylor et al. [25] proposed the TCK model by introducing effective bulk modulus, crack density, and Poisson's ratio on the basis of the GK model, established the relationship between damage variable and crack density, and revealed the law of crack damage development under blasting. Industrial practice in South Africa shows [26] that it is necessary to reduce the average energy release rate caused by mining to control the occurrence of rock burst and reduce the harm caused by rock burst.

Based on the working face 401111 of Hujiahe Coal Mine, this paper studies the synergistic effect of borehole pressure relief and anchoring by theoretical analysis and engineering practice, which provides the basis for the formulation of mine safety production and rock burst control measures. The control countermeasures are studied to provide reference for surrounding rock control of roadway in the similar working face. 
Since 2011, in Hujiahe Mining Co., Ltd., mine pressure is repeatedly appearing in the process of tunneling and working face mining in each crossheading, and the sound of "coal burst" is intense. Subsequently, abnormal pressure phenomena such as cable (rod) breaking, roof subsidence, floor heave, and roof leakage have occurred, which has seriously affected the mining layout, production continuity, and support cost of the mine.

\section{The Induced Mechanism of Dynamic and Static Load Superposition of Rock Burst}

The excavation of underground coal body causes the disturbance of the stress field, and the stress concentration area exceeding the original rock stress is formed in the coal body in front of the work and around the roadway horizontally, namely, the supporting stress area. At the same time, the excavation causes the destruction and migration of overburden rock and forms the caving zone, fracture zone, bending subsidence zone, and original stress zone vertically [27].

Under the condition of deep high geostress, the original rock is in the state of quasi-hydrostatic pressure, so the change of the stress environment of coal and rock mass in front of deep work starts from the state of quasi-hydrostatic pressure. With the advancement of the working face, the abutment pressure (vertical stress) in the coal seam gradually increases from the state of three-dimensional isostatic hydrostatic pressure to the peak stress and then enters the pressure relief state with the destruction of the coal body [28]. The vertical stress gradually decreases until the single-pressure residual strength state at the coal wall. The real stress path is shown in the OABDE path in Figure 1. On the contrary, the horizontal stress is gradually reduced from the hydrostatic pressure state of three-dimensional equal pressure to 0 , namely, pressure relief. The real stress path is shown in the GF path in Figure 1. From the diagram, it can be seen that the underground mining activities, the stress response of coal and rock mass to mining activities, such as coal cutting, frame shifting, mechanical vibration, blasting, roof and floor breaking, coal and roof structure instability, gas outburst, coal burst, fault slip, and other mine vibration loads, are superimposed with the supporting stress (static load) of the coal body around the stope and roadway. Once the bearing limit of the coal body is exceeded, it is easy to produce coal and rock dynamic disasters. The mechanism of dynamic and static load superposition of rock burst can be expressed as follows:

$$
\sigma_{s}+\sigma_{d} \geq \sigma_{b \min } .
$$

In the formula, $\sigma_{s}$ is the static stress of the coal and rock mass, $\sigma_{d}$ is the mine vibration load, and $\sigma_{b \text { min }}$ is the critical stress of rock burst.

\section{Analysis on Surrounding Rock Control Principle of Rock Burst Roadway}

3.1. Principle of Large Diameter Pressure Relief. The principle of large diameter borehole pressure relief is similar to the principle of deep hole blasting pressure relief. The large diameter borehole pressure relief is through the construction of large diameter drilling in high stress coal or roadway surrounding rock, which destroys the original stress state and integrity of coal and rock, expands the range of the plastic zone around the roadway, reduces the high stress of roadway surrounding rock and transfers to the depth of roadway surrounding rock, and eliminates the impact risk. Large diameter boreholes are constructed in the coal body with high stress, and the original equilibrium state of the coal body around the borehole is broken. Cracks are generated around the borehole, and rupture occurs, which leads to the rupture and loosening of the coal body far from the borehole. A fracture zone and plastic zone can be formed in the coal body. If a plurality of large diameter boreholes is implemented in the coal body, the fracture zone or plastic zone of the coal body around the borehole is connected to each other, and a larger range of pressure relief zones and pressure relief zones will be formed in the coal body, which plays a role in preventing punching and solving danger. In addition, the borehole space and the surrounding loose coal can also provide enough expansion deformation compensation space for the stress release of high stress coal, which can attenuate the vibration wave generated by the mine earthquake and make the vibration wave energy reaching the roadway decay rapidly. Even if the deep impact occurs, the loose coal around the roadway will also play a role in protecting the roadway. The principle of large diameter borehole pressure relief is shown in Figure 2.

\subsection{Pressure Relief-Anchorage Collaborative Control} Principle. The surrounding rock reinforcement technology of thick-layer high-strength bearing ring is adopted to construct the pressure-bearing structure to strengthen the surrounding rock. The single hole (one row and one hole) or less holes are used to unload the pressure. The drilling length and row spacing are appropriately selected to ensure that the drilling construction speed matches the tunneling speed while achieving the pressure relief effect. The stress distribution around the roadway is optimized to transfer to the deep, improve the stress environment of the shallow bearing structure, and improve the anchorage efficiency.

Borehole pressure relief makes the surrounding rock stress transfer to a deeper position and forms the pressure relief zone to cut off the transmission of mining stress wave so that the surrounding rock in the process of excavation and support is in a good stress environment, which is very beneficial to the construction of thick high-strength bearing ring, so as to form the mechanism of "strengthening support in shallow zones" and "deep pressure relief in deep zones" in the surrounding rock of the roadways [29], as shown in Figure 3.

\section{General Situation of Work Face}

4.1. Position of Working Face. The specific underground location of working face 401111 is 402 panel in the north, boundary coal pillar of Hujiahe and Xiaozhuang minefield in the south, protection coal pillar of Jinghe and expressway in the west, and 401101 fully mechanized top coal caving face in the east. The position of working face 401111 is shown in Figure 4. 


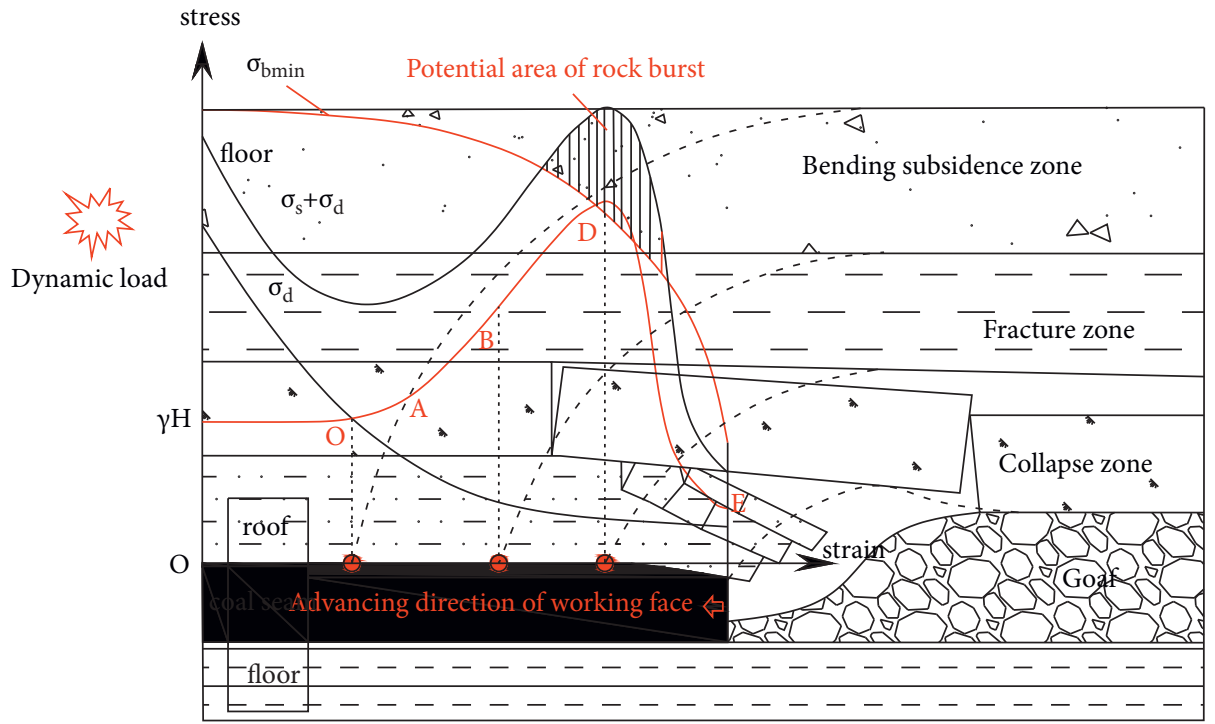

Figure 1: Mechanism of rock burst induction.

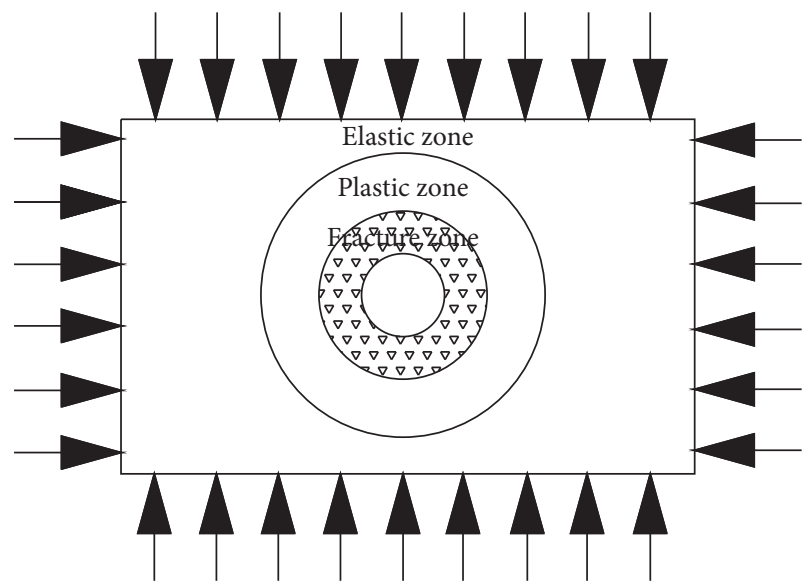

Figure 2: Pressure relief diagram of large diameter boreholes.

4.2. Occurrence Characteristics of Coal (Rock) Layer. Coal seam $4 \#$ in 401111 working face is stable, the coal seam is nearly horizontal, the thickness is $15.0 \sim 27.0 \mathrm{~m}$, and the average thickness is about $24 \mathrm{~m}$. The coal seam structure is simple, generally containing two layers of gangue. The gangue is located in the middle and upper part of the coal seam, and the thickness of gangue is generally less than $0.3 \mathrm{~m}$. In addition, vertical joints and fractures are often accompanied in coal seams, and $2-5 \mathrm{~cm}$ calcite veins are filled in fractures. 4\# coal seam is a stable coal seam. The coal is black, semibright, glossy asphalt, layered structure, banded structure, and shell-like or ladder-like fracture, and the apparent density is $1.36 \mathrm{~g} / \mathrm{cm}^{3}$, which is high-quality power, gasification coal, and civil fuel.

4.3. The Lithology of Floor and Binching of Coal Bed. Immediate roof is siltstone and sandy mudstone which are easy to fall, thickness of about $8 \mathrm{~m}$, rock and saturated compressive strength is $0.4 \sim 25.8 \mathrm{MPa}$. The basic roof is medium sandstone and coarse sandstone, and its saturated

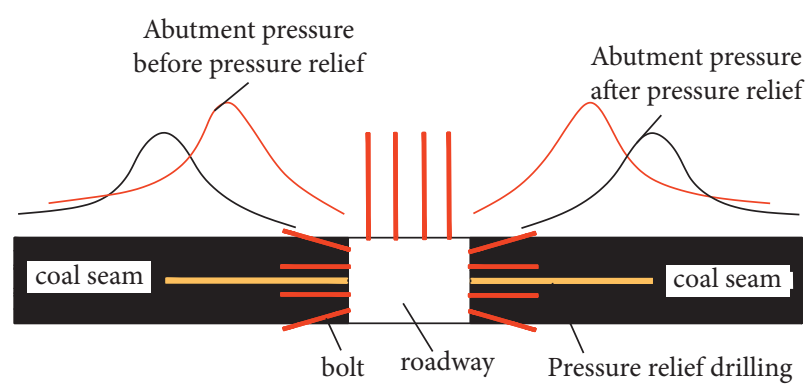

FIgURE 3: "Pressure relief-anchorage" cooperative control principle.

compressive strength is $6.7 \sim 17.2 \mathrm{MPa}$. No obvious pseudotop exists.

The direct bottom is bauxite mudstone with a thickness of about $4.6 \mathrm{~m}$. It is light gray, smooth, exquisite, and lumpy and contains oolitic pyrite nodules. It is easy to soften in water, belonging to unstable and hard. The pseudobottom is located at the bottom of the coal seam, mainly carbonaceous mudstone. According to the detailed geological report, this section is not treated as a coal seam, but treated as other layers. The thickness of this section is $0.5 \mathrm{~m}-0.8 \mathrm{~m}$, generally $0.6 \mathrm{~m}$.

\section{Analysis on Influencing Factors of Roadway Deformation}

5.1. Depth. The buried depth of the roadways in working face 401111 is about $600 \mathrm{~m}$. The original vertical stress is about $15.50 \mathrm{MPa}$, larger stress in original rock. According to the ground stress test results of Hujiahe Coal Mine, the maximum principal stress of Hujiahe Coal Mine is between 18.04 $\mathrm{MPa}$ and $33.87 \mathrm{MPa}$, which belongs to high and superhigh stress areas. Roadway is in a high stress environment, and surrounding rock deformation shows elastic, plastic transformation, and rheological and expansion characteristics. At the same time, the characteristics of deep 


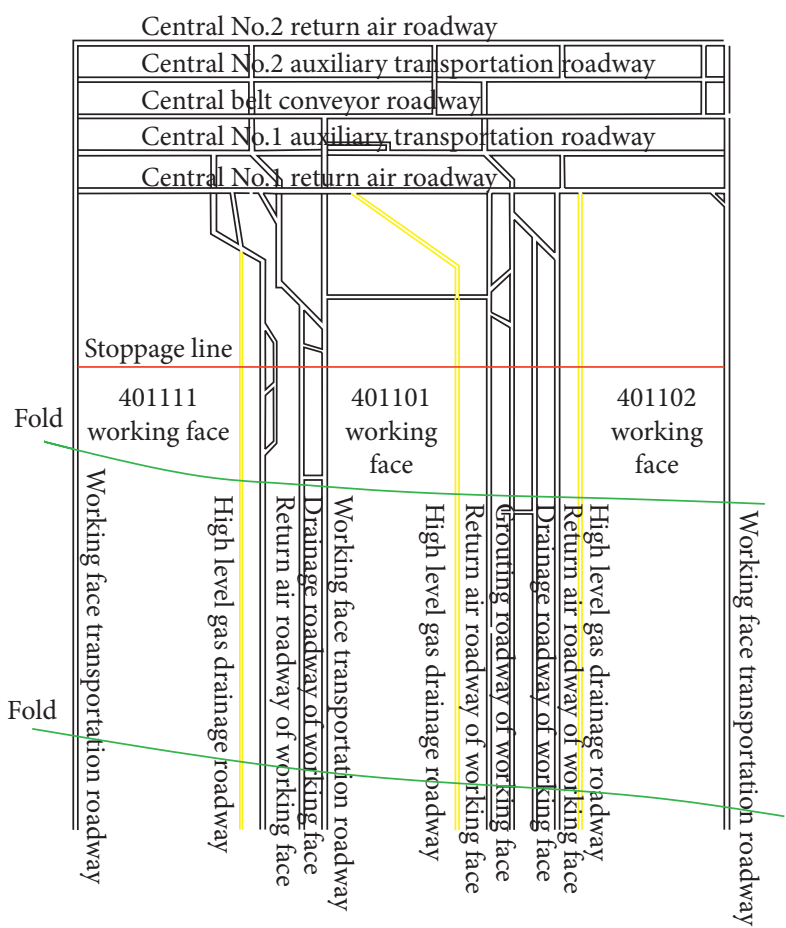

FIgURE 4: Location of Hujiahe 401111 working face.

roadway surrounding rock deformation speed, long duration, asymmetric deformation, and large range of loose and broken surrounding rock bring great difficulties to the control of surrounding rock.

5.2. Fold. According to "《Three-dimensional seismic exploration report in the first mining area of Hujiahe mine 》," there are two synclines in the working face, named A1 syncline and A2 syncline. The A1 syncline is developed in the range of $394 \mathrm{~m}-491 \mathrm{~m}$ north of the working face. The axial direction is northeast, and the axial plane tends to southwest. The fluctuation range is $3-10 \mathrm{~m}$, and the stratum is relatively flat. The A2 syncline is developed in the south $224 \sim 301 \mathrm{~m}$ range of No. 1 return air roadway in the central working face. The axial direction is basically northeast, and the axial surface tends to southwest. The fluctuation range is $1 \sim 7 \mathrm{~m}$, and the inclination angle is about $1 \sim 3$, which is a reliable fold. In the process of fold formation, many fracture structures are often accompanied, which makes the integrity and continuity of coal seam worse. Due to the development of roof cracks, under the action of mine pressure, cracks are further expanded, and graben or ladder structures are often formed in the fold crankshaft. These structures destroy the integrity and continuity of coal seam roof, resulting in a complex roof structure, which brings great difficulties to roof management.

5.3. Coal Seam Thickness. The working face 401111 coal seam has thickness of about $15.0 \sim 27.0 \mathrm{~m}$, and the average thickness is about $24 \mathrm{~m}$, using the fully mechanized caving mining method. The mining height is $3.5 \mathrm{~m}$, and the caving height is $10 \mathrm{~m}$, reserved top coal is $9 \mathrm{~m}$. The mining roadway is excavated along the bottom plate, the top coal thickness is large, and the cracks are developed. There are nearly $20 \mathrm{~m}$ top coal above the roadway, which is the main source of seismic events and energy release. Excessive mining height not only makes the fracture height of the main roof large but also makes the goaf unable to be compacted. The residual abutment pressure of the goaf is large, and the rotary subsidence of the key block is overlapped with the coal pillar, which further causes the stress concentration of the coal pillar and intensifies the deformation of the roadway.

5.4. Mining Influence. Affected by the stress disturbance and residual abutment pressure of goaf in working face 401101 of adjacent working face during roadway excavation and mining, the plastic zone of thick top coal roof expands, the deformation increases, and the cracks further develop and expand. The original rock stress zone in the coal pillar disappears, the damage degree intensifies and gradually becomes a plastic state of complete failure. Only residual strength is retained, the bearing capacity decreases sharply, and the roadway support is difficult.

\section{Numerical Simulation}

6.1. Establishment of Numerical Model. Taking the geological conditions of return airway in working face 40111 of Hujiahe Coal Mine in Shaanxi Province as the geological prototype, a numerical model with mining depth of $600 \mathrm{~m}$ was established by FLAC3D. According to the measured geostress value in Hujiahe Coal Mine, $15 \mathrm{MPa}$ stress is applied in the vertical direction, $30 \mathrm{MPa}$ stress is applied in the $x$ direction, and $26 \mathrm{MPa}$ stress is applied in the $y$ direction. The deformation characteristics of roadway under such geological 
TABLE 1: Physical and mechanical parameters of each rock layer.

\begin{tabular}{|c|c|c|c|c|c|c|}
\hline Lithologic characters & Thickness & Density & Shear modulus $(\mathrm{GPa})$ & Bulk modulus (GPa) & Cohesion (MPa) & Angle of internal friction \\
\hline Siltstone & 6.3 & 2570 & 5.9 & 21.1 & 2.3 & 39 \\
\hline Sandy mudstone & 21.8 & 2530 & 5.7 & 20.5 & 10.6 & 38 \\
\hline Post office box stone & 0.9 & 2440 & 6.46 & 22.6 & 10.1 & 40.7 \\
\hline Sandy mudstone & 7.8 & 2530 & 5.7 & 20.5 & 10.6 & 38 \\
\hline Coal seam & 24 & 1360 & 4.07 & 7.1 & 2.28 & 35.8 \\
\hline Mudstone & 4.7 & 2540 & 4.54 & 17.06 & 0.8 & 30 \\
\hline Siltstone & 4.8 & 2570 & 5.9 & 21.1 & 2.3 & 39 \\
\hline Mudstone & 26 & 2540 & 4.54 & 17.06 & 0.8 & 30 \\
\hline
\end{tabular}

conditions, the control effect of bolt (cable) anchorage efficiency on surrounding rock deformation, and the control effect of pressure relief-anchorage synergy on surrounding rock deformation of roadway were studied. Three schemes were used to simulate the deformation of roadway. The scheme 1 simulates the deformation of roadway without support and pressure relief, the scheme 2 simulates the deformation of roadway with support and without pressure relief, and the scheme 3 simulates the deformation of roadway with support and pressure relief.

The model size is $300 \times 30 \times 96.3 \mathrm{~m}$, and excavation roadway size is $5.6 \mathrm{~m}^{*} 3.7 \mathrm{~m}, 30 \mathrm{~m}$ from working face. The excavation of the working face is based on the actual mining situation of 401111 working face in Hujiahe Coal Mine. Mining height is $3.5 \mathrm{~m}$. The caving height is $10 \mathrm{~m}$. The actual excavation height is $13.5 \mathrm{~m}$. The working face length is $150 \mathrm{~m}$. Pressure relief measures are as follows: construction of large diameter pressure relief borehole in two sides of roadway, hole depth $15 \mathrm{~m}$, aperture $120 \mathrm{~mm}$, borehole inclination $0^{\circ}$, borehole spacing $1.4 \mathrm{~m}$, floor construction of large diameter pressure relief borehole depth $10 \mathrm{~m}$, borehole inclination $60^{\circ}$, borehole diameter $120 \mathrm{~mm}$, and borehole spacing $1.4 \mathrm{~m}$. According to laboratory measurements, the physical and mechanical parameters of each rock layer are shown in Table 1. The numerical model adopts the Mohr-Coulomb model. The model is simply supported around and fixed at the bottom. The vertical stress of $15 \mathrm{MPa}$ is applied at the top of the model (600 $\mathrm{m}$ from the surface) to simulate the self-weight load of the overlying strata. The numerical simulation model is shown in Figure 5.

6.2. Plastic Zone Distribution. The distribution of the plastic zone of return air roadway of working face 40111 is shown in Figure 6 . The stress produced by working face mining is concentrated in the coal pillar, and a large plastic zone is produced. The roadway support and pressure relief methods further reduce the plastic zone. The application of pressure relief measures can effectively reduce the deformation of roadway floor.

6.3. Vertical Pressure Distribution. The vertical stress distribution of the air return roadway in working face 401111 is shown in Figures 7 and 8. After taking pressure relief measures, the stress concentration around the roadway is significantly reduced and transferred to the deep. The top

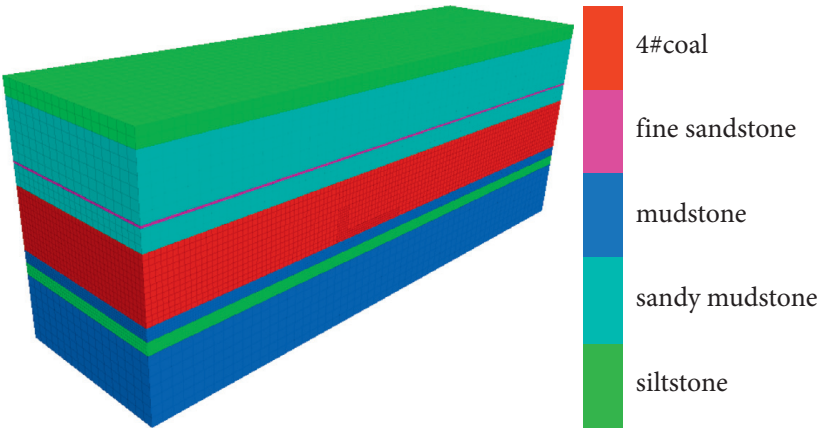

FIgURE 5: Numerical simulation model.

coal stress of $20 \mathrm{~m}$ thick above the roadway is effectively reduced, which greatly reduces the possibility of impact failure of the roadway. Maximum vertical stress on coal pillar side decreased from $52.9 \mathrm{MPa}$ to $39.2 \mathrm{MPa}$.

6.4. Vertical Displacement Distribution. The vertical displacement distribution of air return roadway in working face 401111 is shown in Figures 9 and 10. The numerical simulation results show that compared with scheme 1 , the roof subsidence of scheme 3 is reduced by $33 \%$, the floor heave is reduced by $24 \%$, the deformation of left side is reduced by $75 \%$, and the deformation of right side is reduced by $10 \%$. Compared with scheme 2 , the roof subsidence of scheme 3 is reduced by $14 \%$, the floor heave is reduced by $12 \%$, the deformation of left side is reduced by $39 \%$, and the deformation of right side is reduced by $4 \%$. After the implementation of the new support and pressure relief scheme, the surrounding rock of the return air roadway is basically stable, which shows that the new support scheme design is reasonable and reliable. It has a good reference significance for the surrounding rock control of the same type of mine roadway.

\section{Countermeasures of Surrounding Rock Control}

\subsection{Strengthening Support Measures for the Roadways in Working Face 401111}

7.1.1. Temporary Support. Three ring-type forward probe beams were used. The forepoling bar was made of 4 inch steel tubes, $4.0 \mathrm{~m}$ in length and $4 \mathrm{~mm}$ in wall thickness. Each preprobe beam is fixed by three rings, and the rings are twisted on the top anchor according to the row spacing 
Scheme 1

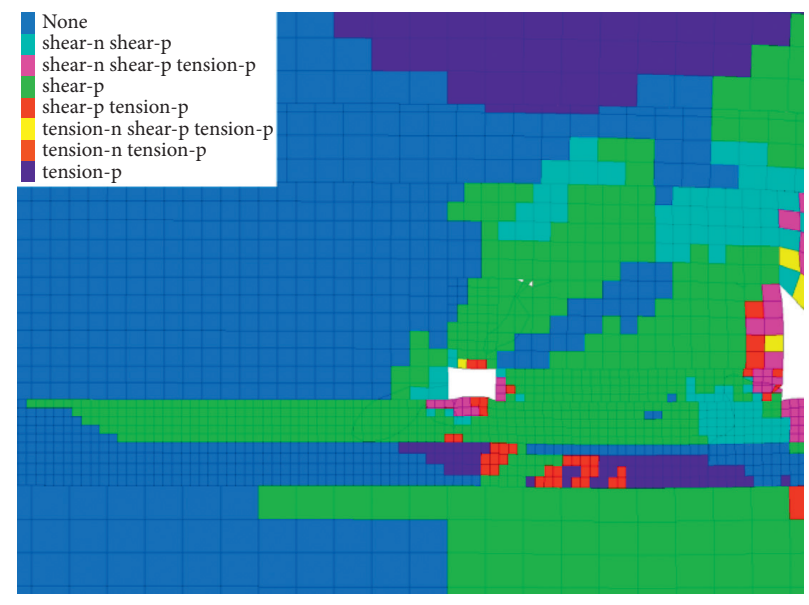

Scheme 2

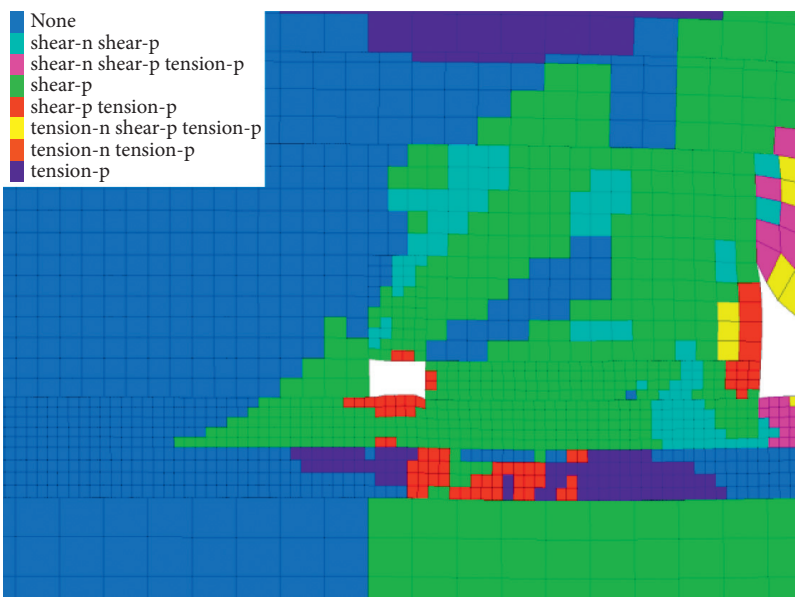

Scheme 3

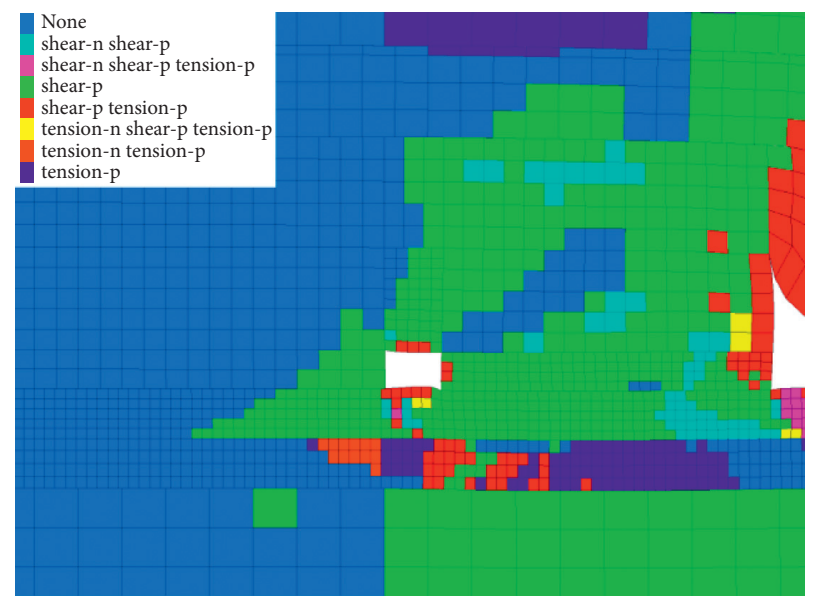

Figure 6: Distribution of the plastic zone. (a) Scheme 1. (b) Scheme 2. (c) Scheme 3. 
Scheme 1

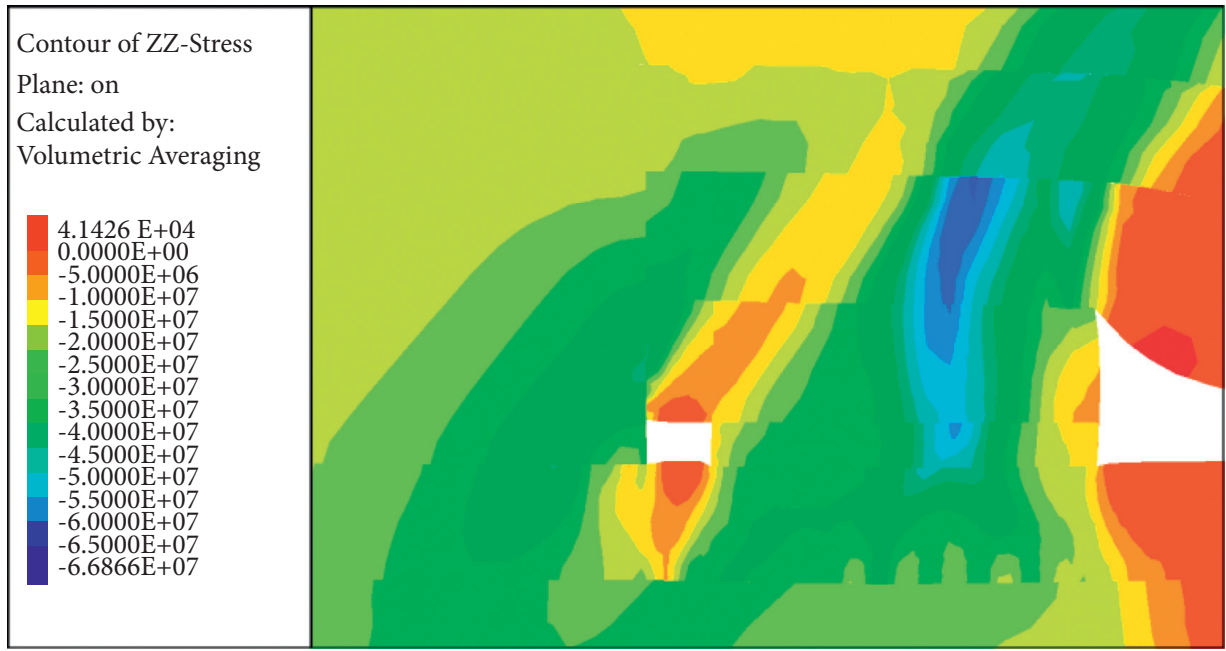

Scheme 2

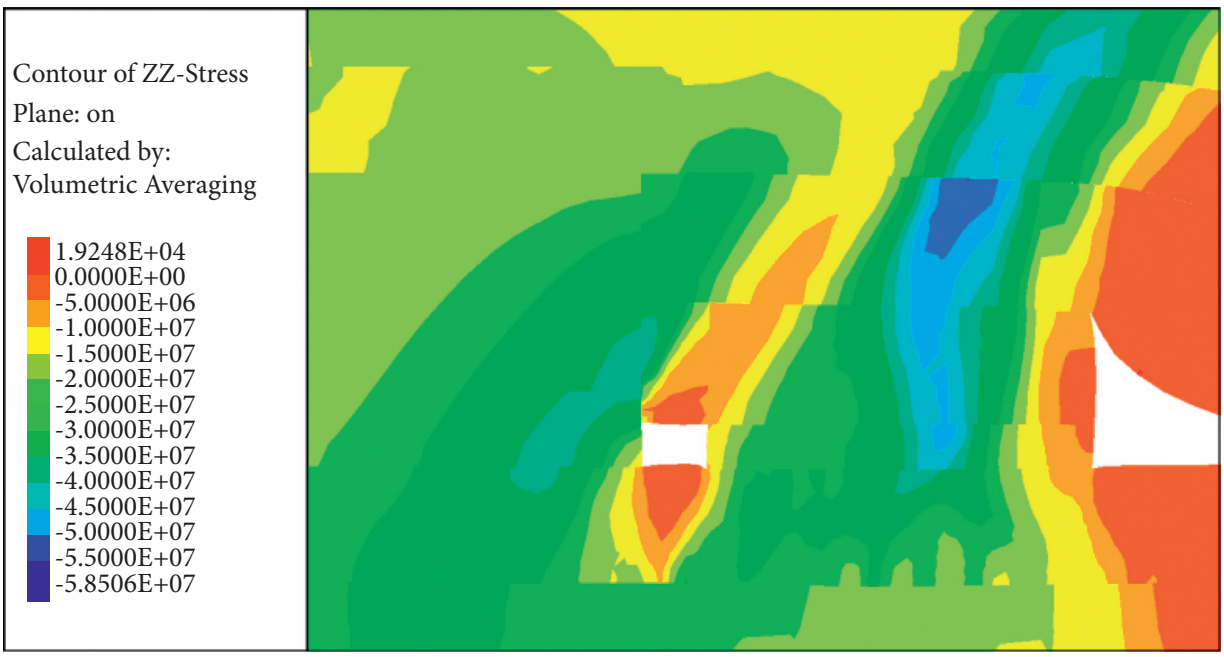

Scheme 3

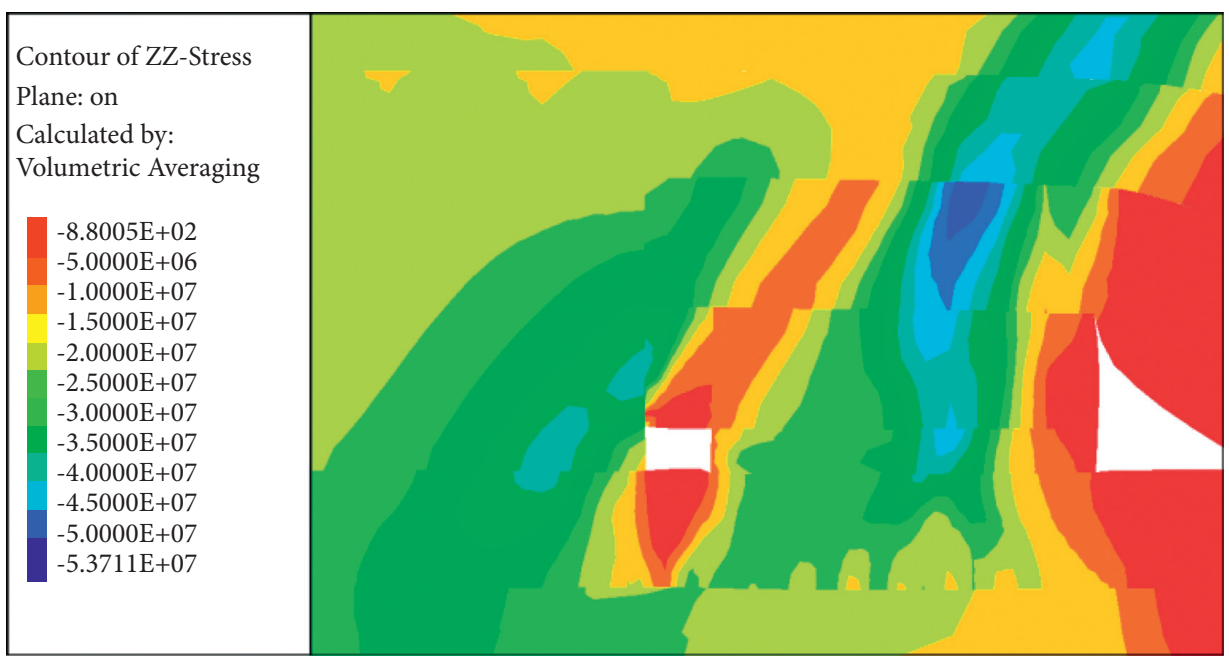

Figure 7: Vertical stress distribution. (a) Scheme 1. (b) Scheme 2. (c) Scheme 3. 


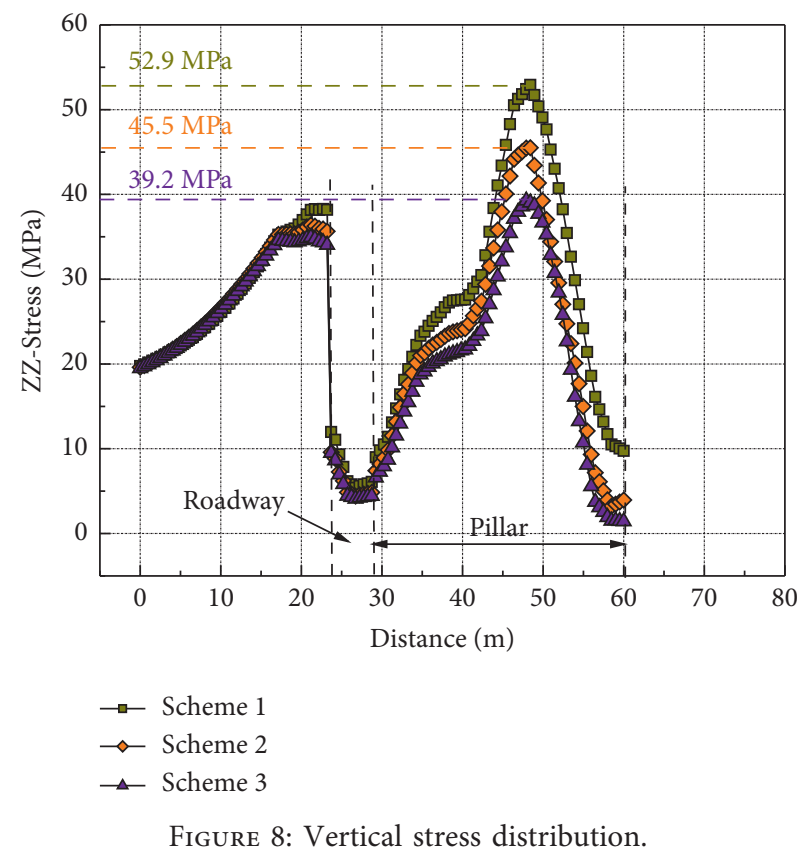

between the anchors and fixed with board beam placed on front beam. During normal construction, the hanging ring spacing is $0.8 \mathrm{~m}$, one to the other two forward beam spacing is not more than $1400 \mathrm{~mm}$, and construction should move forward in time. The maximum distance between the bolt and the head is $300 \mathrm{~mm}$, and the maximum distance between the bolt and the head after excavation is $1900 \mathrm{~mm}$.

An antislide hook should be fixed at one end of each steel pipe to prevent the sliding of the front beam in the process of rise or dip excavation. The antisliding hook is processed with $500 \mathrm{~mm}$ long $\varphi 12 \mathrm{~mm}$ steel wire, and the hook ends are processed with steel bars at both ends of the wire rope. One end of the antisliding hook is fixed on the roof reinforcement mesh, and the other end is fixed on the front probe beam.

7.1.2. Permanent Support. The support form of air return roadway in working face 401111 is bolt mesh shotcrete support outside the stoping line and bolt mesh support inside the stoping line. The roof bolt of roadway adopts the $\varphi 22 \times 2500 \mathrm{~mm}$ left-handed nonlongitudinal reinforcement screw steel bolt. The row spacing between the bolts is $700 \times 800 \mathrm{~mm}$ rectangular arrangement, and the exposed length is $10-40 \mathrm{~mm}$. The anchor plate adopts Q235 steel plate, and the specification is $150 \times 150 \times 12 \mathrm{~mm}$. Each bolt is anchored by one K2360 and one Z2360 anchoring agent. Eight top bolts are fixed with $\mathrm{W}$ steel belt, and the specification is $5100 \times 280 \times 3 \mathrm{~mm}$. The top anchor cable adopts $1 \times 19$ strands of high-strength $\varphi 21.8 \times 7100 \mathrm{~mm}$ steel strand, and the row spacing is $1300 \times 800 \mathrm{~mm}$. The anchor cable tray is processed by Q235 steel plate $300 \times 300 \times 16 \mathrm{~mm}$ disc tray, and KM22 lock and guide ring are used. Each anchor cable is anchored with $1 \mathrm{~K} 2360$ and 2 Z2360 anchorages. The anchor cable lock is protected by using $500 \mathrm{~mm}$ long 16 \# wire to wind at least four circles at the position of the steel strand below the lock and then fixed to the metal mesh. The lower side of the steel belt is supported by $\Phi 15.24 \times 3500 \mathrm{~mm}$ anchor cable, and the row spacing between anchor cables is $800 \times 800 \mathrm{~mm}$ rectangular arrangement. Five anchor cables are designed for each side. The supporting plate adopts Q235 steel plate, the specification of which is $150 \times 150 \times 12 \mathrm{~mm}$. Two steel ladders are used for overlapping, with $\varphi 14$ round steel processing. The schematic diagram of roadway support is shown in Figure 11.

7.2. Pressure Relief Measures of Return Airway in Working Face 401111. According to the above analysis results, the corresponding rock burst prevention measures, including head blasting pressure relief, side large diameter pressure relief, and bottom plate large diameter pressure relief measures, are taken as follows:

7.2.1. Pressure Relief by Head-On Blasting. Three boreholes were arranged at the heading face, with the depth of $10 \mathrm{~m}$ and the aperture of $42 \mathrm{~mm}$. Three flower holes were arranged, and the pressure relief was carried out by alternating construction of $b$ and $c$ pressure relief holes. The schematic diagram of the borehole layout is shown in Figure 12.

7.2.2. Large Diameter Pressure Relief of Side. From the roadway mileage of $176 \mathrm{~m}$ (from the No. 1 central return airway, $100 \mathrm{~m}$ from the return airway), the auxiliary side pressure relief hole is started to be constructed, and the main side pressure relief hole is constructed in whole process. Large-diameter pressure relief boreholes were constructed on both sides of return airway. The borehole depth was $15 \mathrm{~m}$, the aperture was $113 \mathrm{~mm}$, the borehole spacing was $1.4 \mathrm{~m}$, the sealing length was $3 \mathrm{~m}$, and the borehole inclination was 0 . The boreholes were arranged in parallel perpendicular to the roadway side. The opening height of the main side was $1.5 \mathrm{~m}$, and the opening height of the accessory side was $2 \mathrm{~m}$.

The schematic diagram of drilling arrangement is shown in Figure 13.

7.2.3. Large Diameter Pressure Relief of Floor. The largediameter pressure relief hole of the floor starts from the opening to the corner cut. The opening position is in the middle of the pedestrian side. The hole depth is $10 \mathrm{~m}$, the inclination angle of the drilling is $60^{\circ}$, the diameter of the drilling is $113 \mathrm{~mm}$, and the spacing of the drilling is $1.4 \mathrm{~m}$. After the drilling construction is completed, the yellow mud is used to seal the hole. The length of the sealing hole is $3 \mathrm{~m}$. The construction requirement of the large-diameter pressure relief hole of the floor should not exceed $45 \mathrm{~m}$.

The schematic diagram of drilling arrangement is shown in Figure 14.

7.3. Pressure ReliefEffect. After taking pressure relief measures in return airway of 401111 working face in Hujiahe Coal Mine, the surrounding rock conditions are obviously improved, and the roadway deformation is effectively controlled. The control effect of surrounding rock after pressure relief in some sections of return airway is shown in Figures 15 and 16. 
Scheme 1

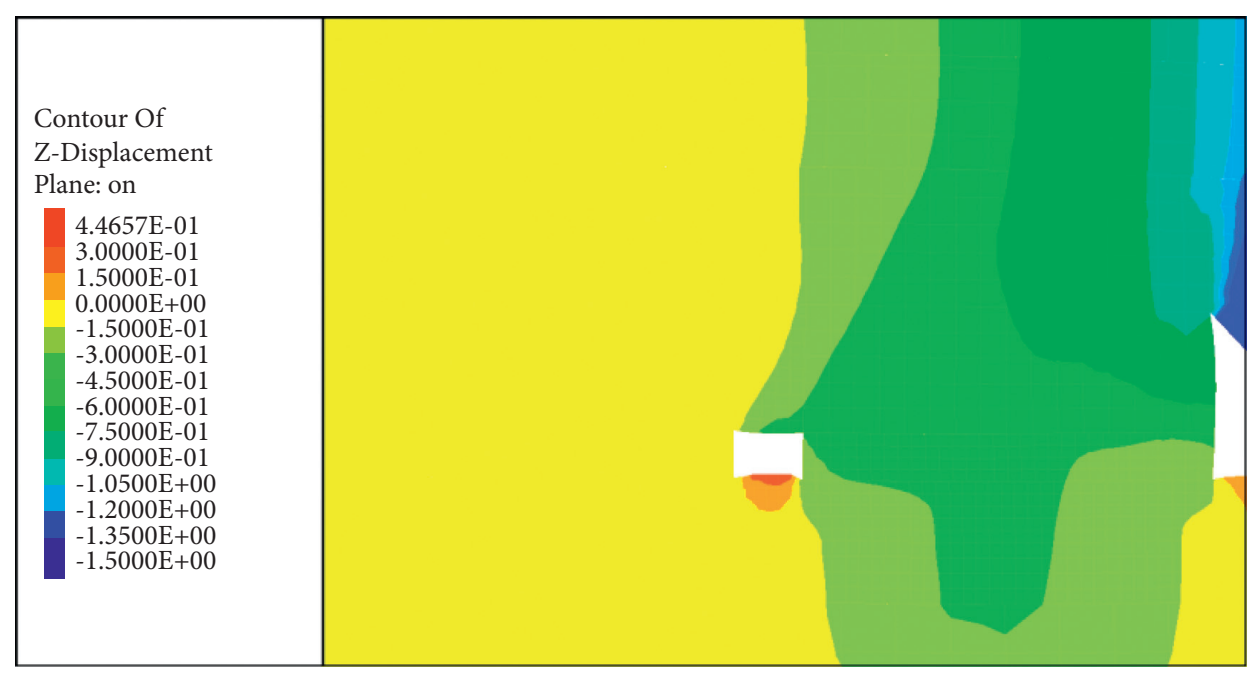

Scheme 2

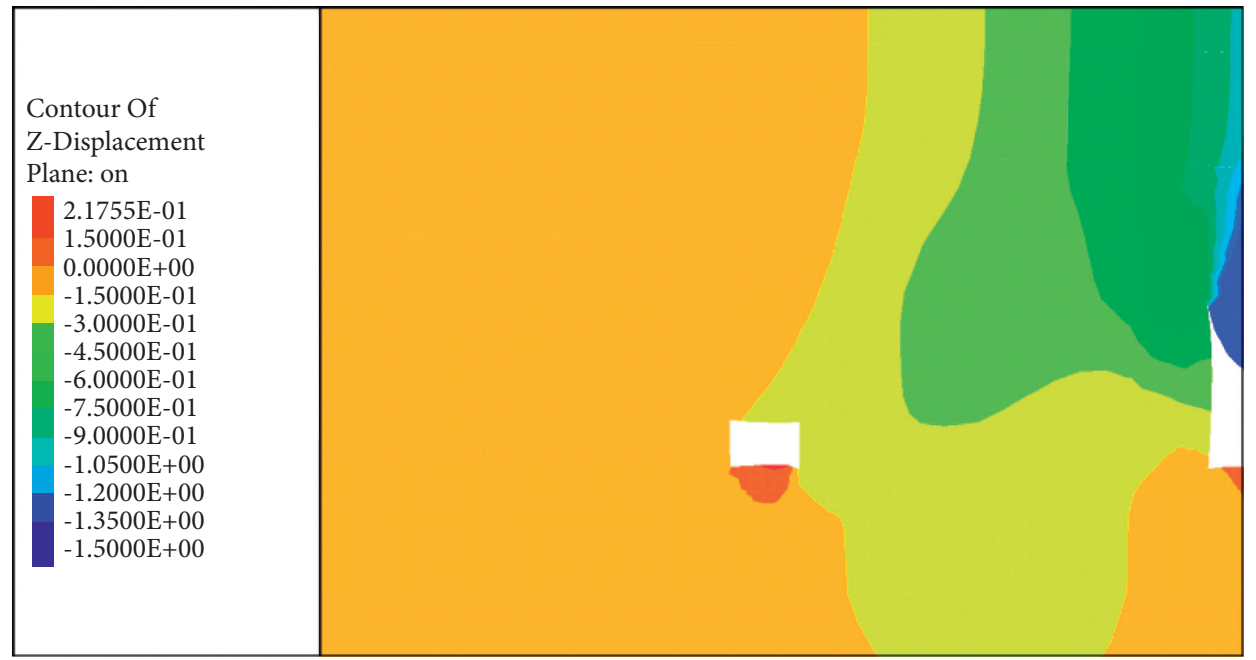

Scheme 3

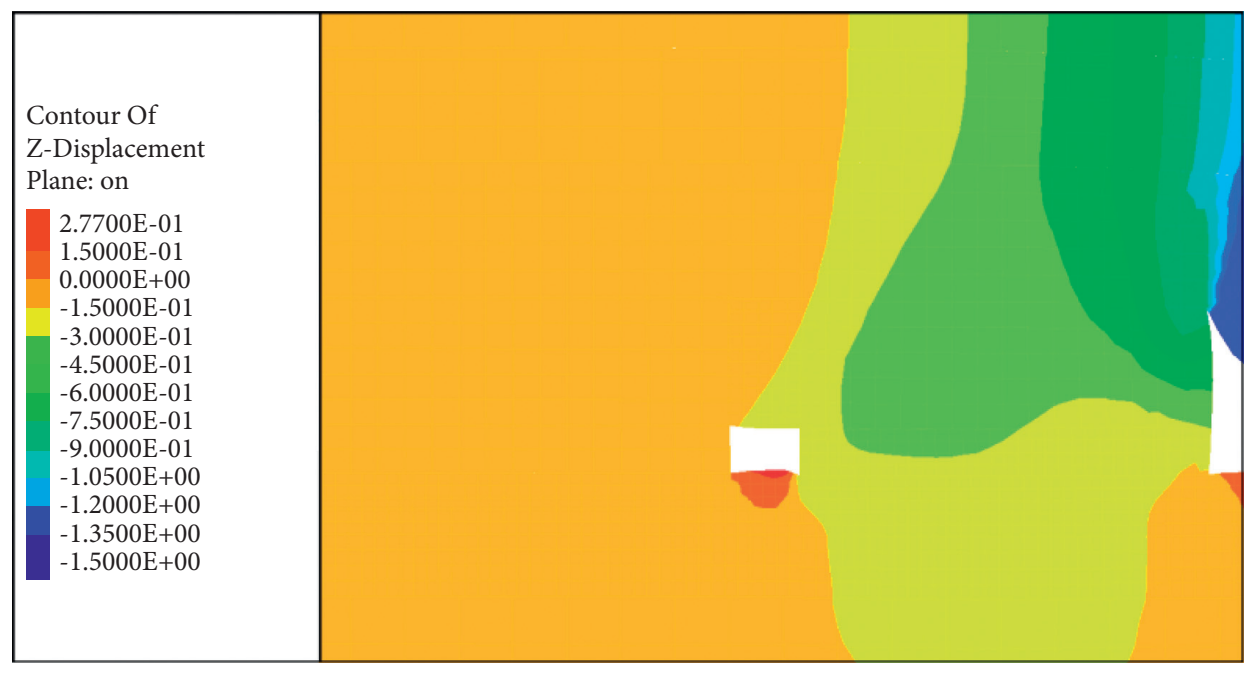

Figure 9: Vertical displacement distribution. (a) Scheme 1. (b) Scheme 2. (c) Scheme 3. 


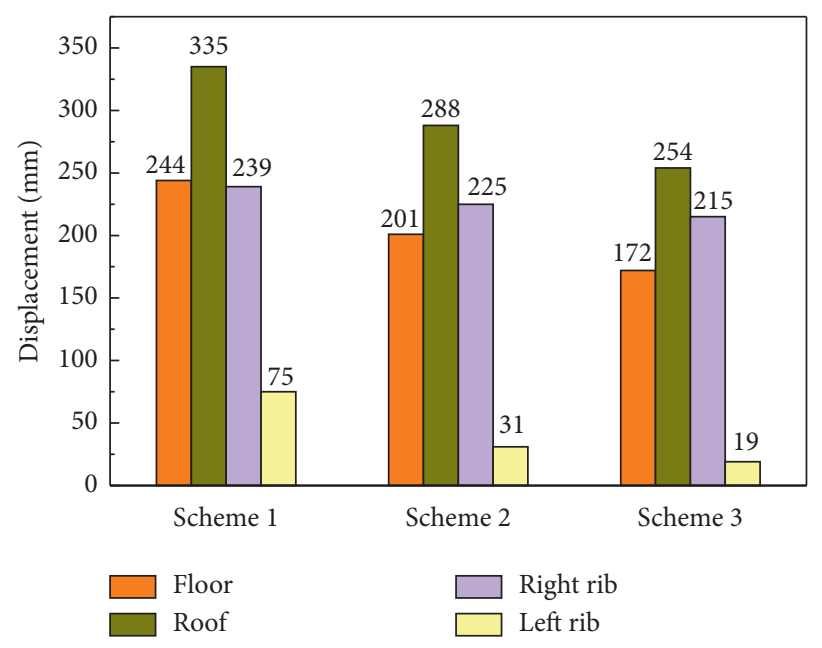

Figure 10: Statistical histogram of roadway deformation.

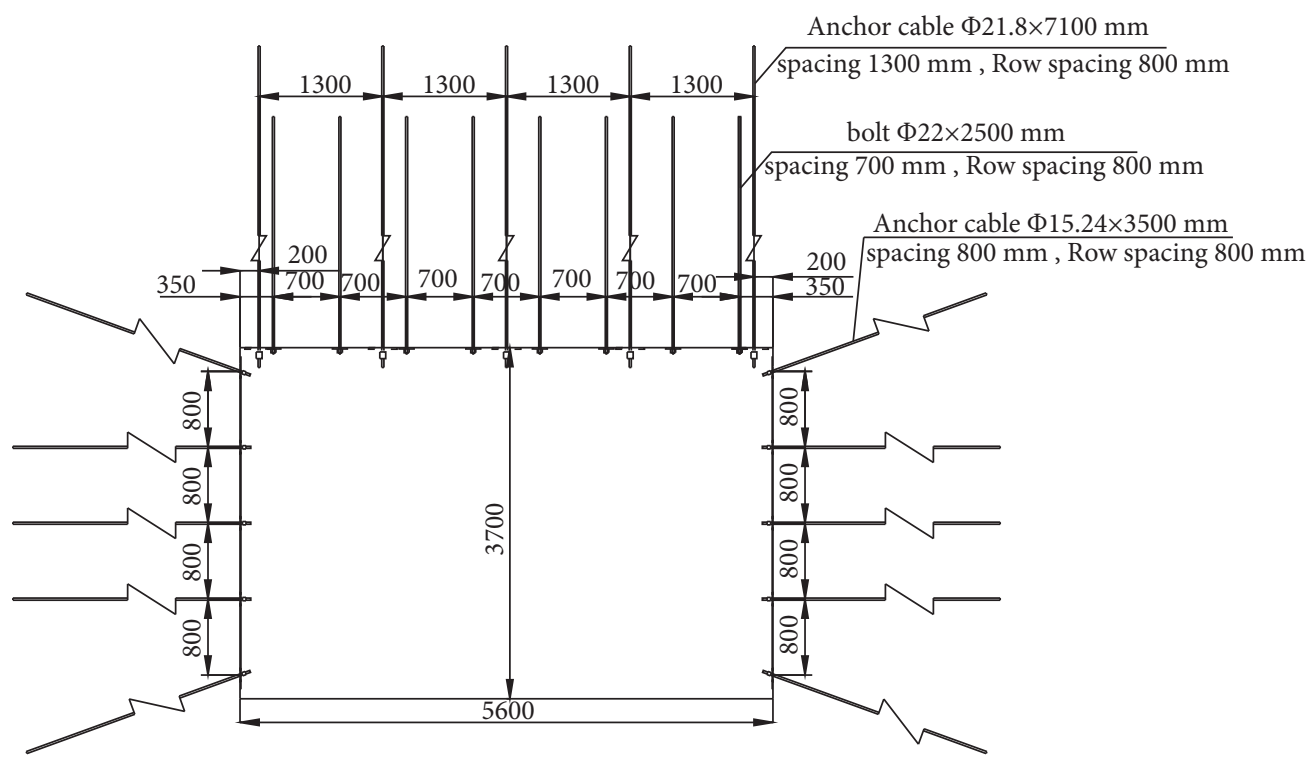

(a)

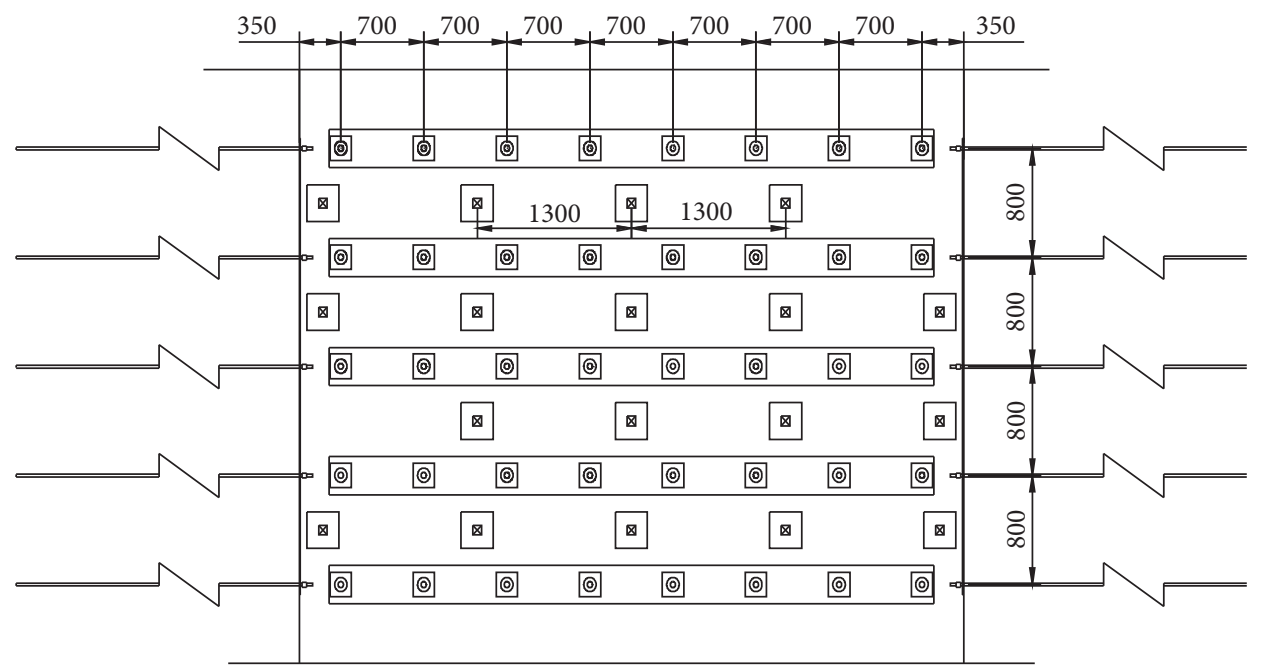

(b)

Figure 11: Continued. 


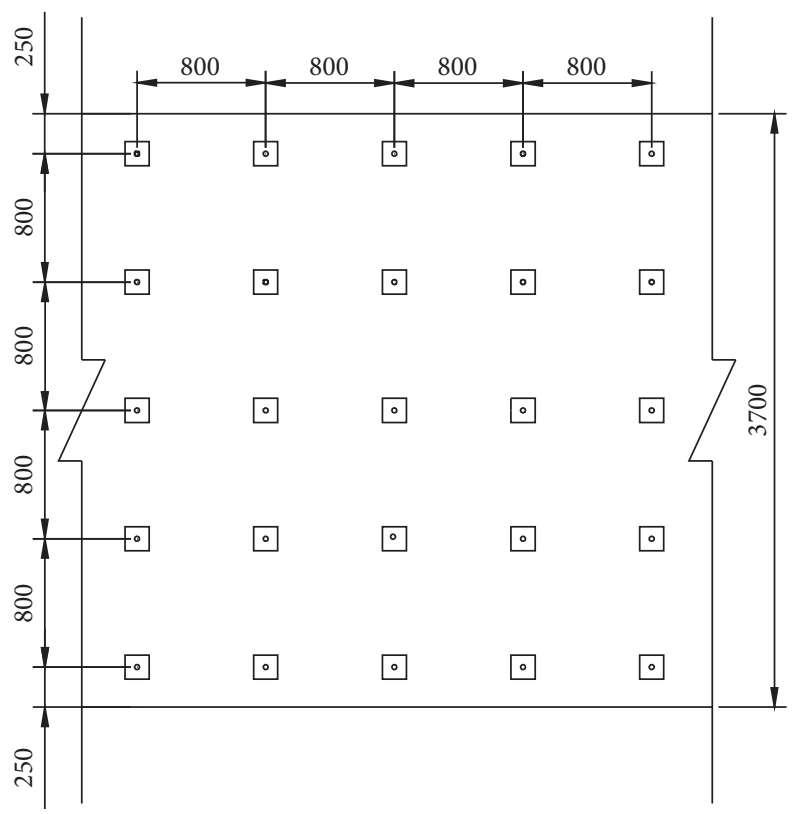

(c)

Figure 11: Roadway support schematic. (a) Section diagram of bolt (cable) support. (b) Top view of roadway support. (c) Side view of roadway support.

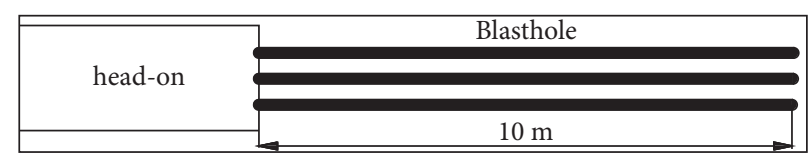

(a)

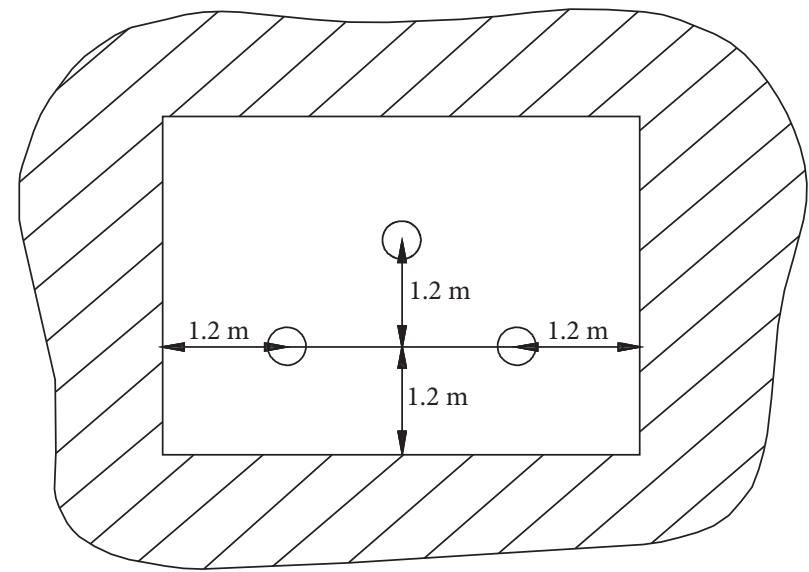

(b)

Figure 12: Continued. 


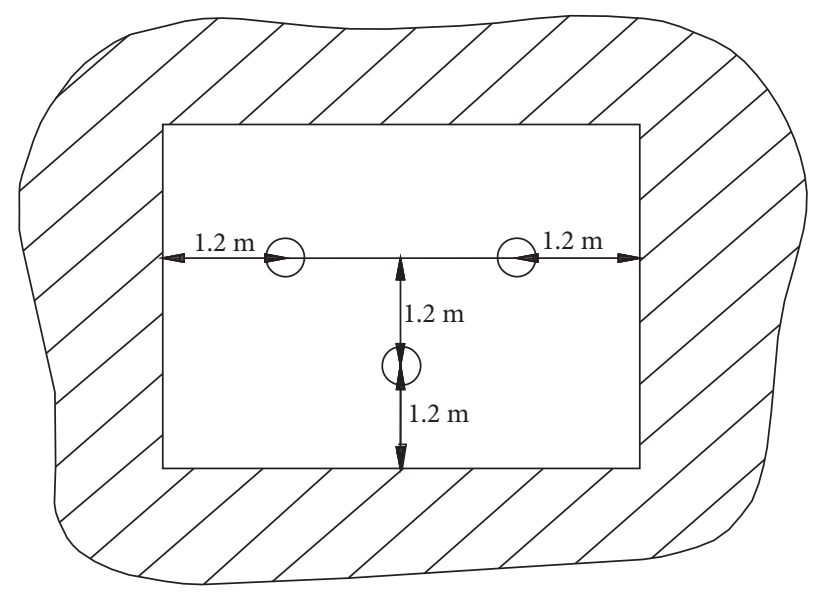

(c)

FIGURE 12: Diagram of the large diameter pressure relief layout of heading face.
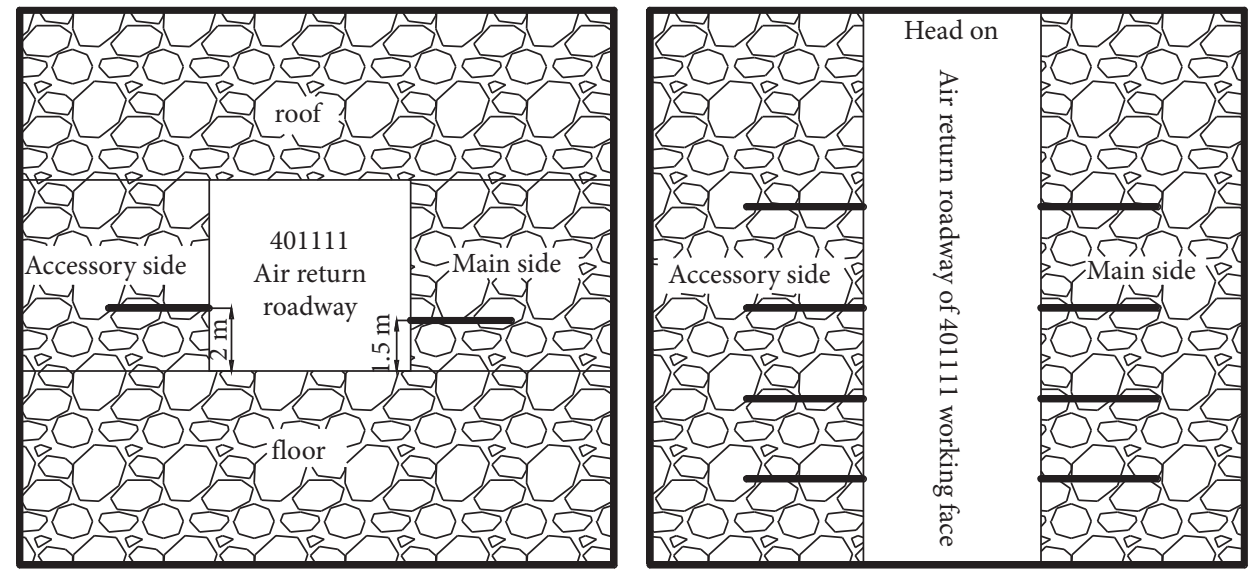

FIGURE 13: Illustration of the borehole layout in bang.
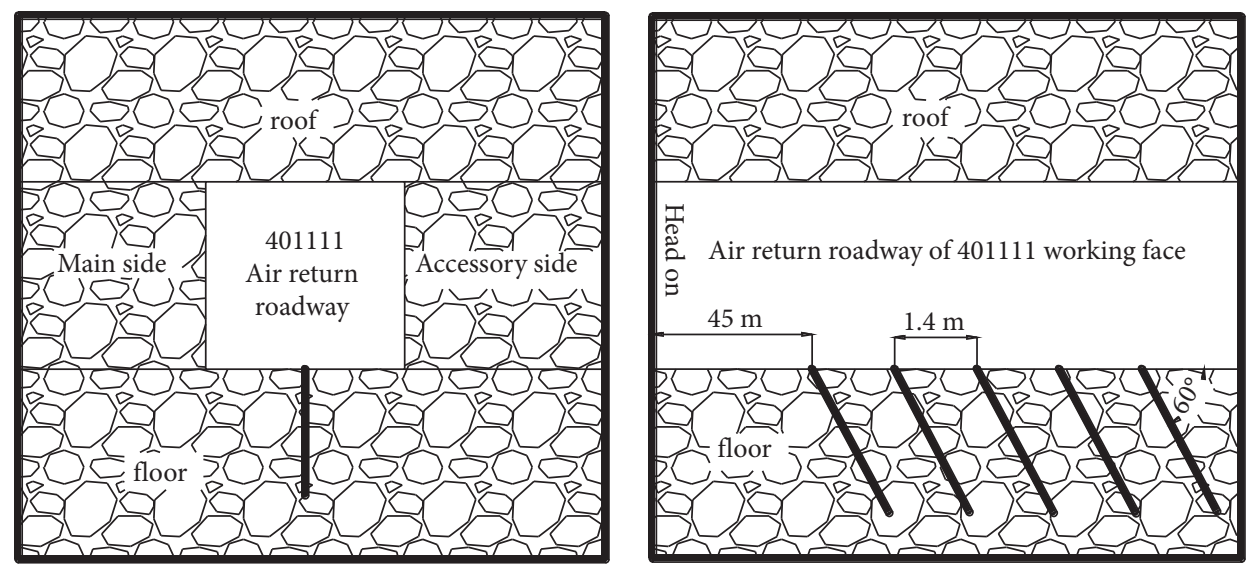

Figure 14: Schematic diagram of the floor drilling layout. 

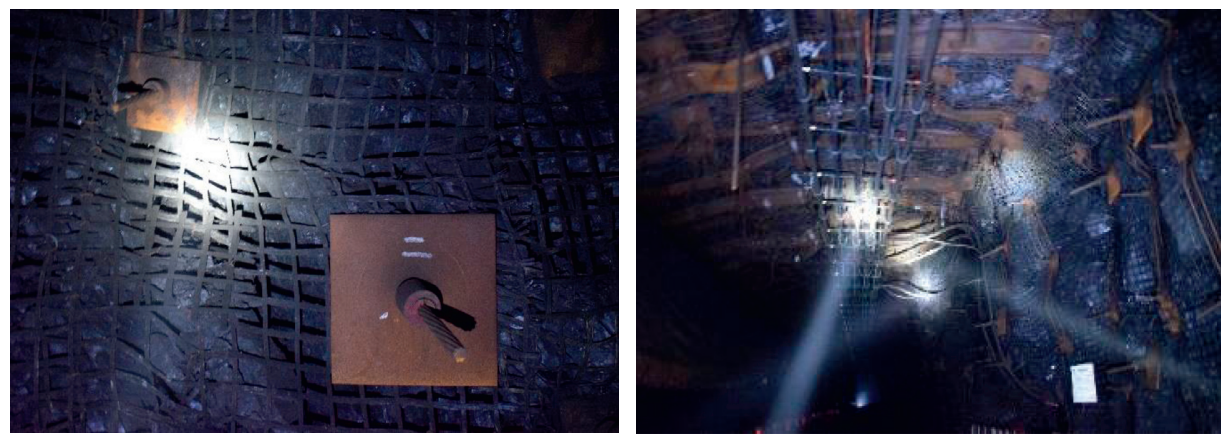

Figure 15: Deformation of $650 \mathrm{~m}$ roof along return airway.
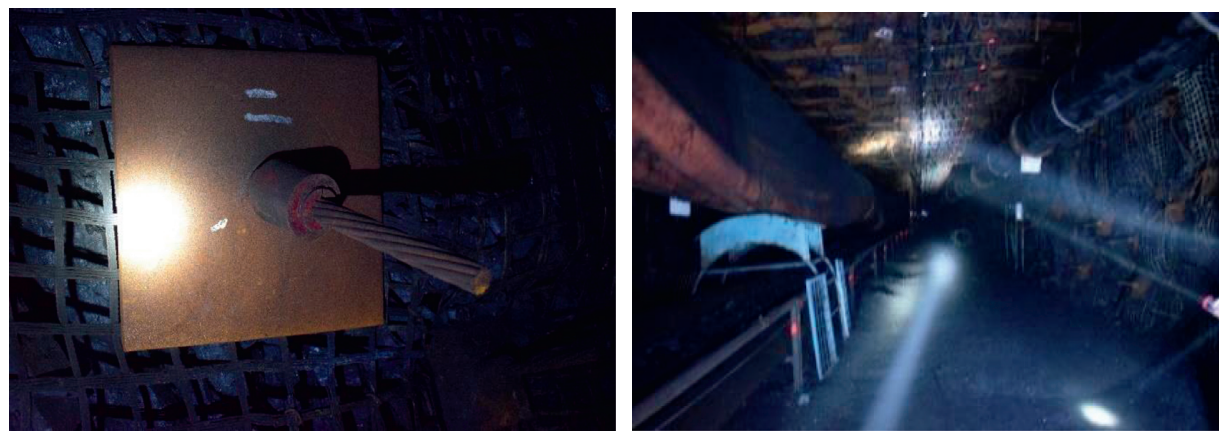

FIGURE 16: Deformation of $600 \mathrm{~m}$ side of return airway.

\section{Conclusion}

(1) After the pressure relief measures were taken in 401111 working face of Hujiahe Coal Mine, the integrity of surrounding rock was destroyed, and the accumulated energy was released. The top coal stress of $20 \mathrm{~m}$ thick above the roadway was effectively reduced, and the stress rise area was basically eliminated. The possibility of roadway impact failure was greatly reduced, which laid a good foundation for the future impact resistance work of the mine.

(2) Measures such as head-on blasting pressure relief, large-aperture pressure relief of sidewall and floor, and strengthening support of 40111 working face in Hujiahe Coal Mine have obvious effects and basically achieved the purpose of rock burst control.

(3) The implementation of large-aperture pressure relief and blasting pressure relief in the roadway sidewall further releases the elastic energy inside the coal body, forms a failure zone in the coal body of the roadway sidewall, and makes the stress increase zone shift to the deep part of the coal body. However, the pressure relief measures in the sidewall reduce the strength of the coal body and form a coal fracture zone, which may also induce the danger of rock burst, resulting in sudden spalling or roof fall. It is suggested that the pressure relief in the sidewall should be constructed ahead of the working face, and the advanced support should be strengthened to adopt the "strong unloading and strong support."
(4) Mining causes large-scale movement of overlying strata and redistribution of stress, which leads to the destruction of coal and rock mass structure, especially the destruction of coal and rock mass around the stope. Long-term dynamic construction disturbance is an important factor in the destruction of surrounding rock of deep coal roadway.

(5) Although the prevention and control of rock burst involves many aspects of work, from the experience of realizing safe production in working face 40111, the "support optimization design based on rock burst prevention" adopted and formed in this mine is reasonable, which lays an important foundation for the successful completion of rock burst prevention.

(6) The high-strength compressive elastic energy stored in the mining surrounding rock, including the compressive elastic energy in the coal and rock mass and the bending elastic energy of the overlying rock in the mining space, is the main force for the occurrence of rock burst. The greater the mining depth is, the higher the strength of the overlying rock is and the greater the possibility of the high-strength compressive elastic energy stored in the compressed coal seam is. To solve the stress concentration fundamentally, the stored elastic energy should be released in advance. Based on the constructed mechanical model, the elastic energy can be released effectively by unloading in the peak area of stress arch. 
(7) In this paper, the collaborative control route of "pressure relief-anchorage" is proposed, which not only takes into account the influence of large diameter drilling on the pressure relief of coal seam in roadway side and the integrity of roof anchor support but also considers improving the stability and support strength of the roof anchor support system, namely, collaborative support.

\section{Data Availability}

The data used to support the findings of the study are included within the article.

\section{Conflicts of Interest}

The authors declare that they have no conflicts of interest.

\section{Acknowledgments}

This work was financially supported by the National Natural Science Foundation of China (Grant no. 51704277), HighLevel Innovation and Entrepreneurship Talents Introduction Program of Jiangsu Province of China, and Natural Science Fundamental Research Program Enterprise United Fund of Shaanxi Province of China (Grant no. 2019JLZ-04).

\section{References}

[1] X. W. Feng, F. Xue, T. Z. Wang, L.-X. Wang, T.-Y. Zhao, and X.-X. Liu, "Reinforcing effects of 3D printed bolts on jointseparated standard soft rock specimens," Composites Part B: Engineering, vol. 193, Article ID 108024, 2020.

[2] G. Y. Si, W. Cai, S. Y. Wang, and X. Li, "Prediction of relatively high-energy seismic events using spatial-temporal parametrisation of mining-induced seismicity," Rock $\mathrm{Me}$ chanics and Rock Engineering, vol. 53, no. 11, pp. 5111-5132, 2020.

[3] Z. Z. Xie, N. Zhang, X. W. Feng, D. X. Liang, Q. Wei, and M. Y. Weng, "Investigation on the evolution and control of surrounding rock fracture under different supporting conditions in deep roadway during excavation period," International, vol. 123, Article ID 104122, 2020.

[4] Q. J. Hao, X. H. Liu, and A. K. Hu, "Research on stress threshold of deep buried coal rock under quasi-static strain rate based on acoustic emission," Advances in Civil Engineering, vol. 2020, pp. 1-13, 2020.

[5] X. J Yang, C. K. Liu, Y. G. Ji, X. Y. Zhang, and S. Wang, "Research on roof cutting and pressure releasing technology of directional fracture blasting in dynamic pressure roadway," Geotechnical \& Geological Engineering, vol. 37, no. 3, pp. 1555-1567, 2019.

[6] J. F. Zhao, Q. J. Han, Y. Dai, and M. Q. Hua, "Study on the electromagnetic design and analysis of axial flux permanent magnet synchronous motors for electric vehicles," Energies, vol. 12, no. 18, p. 3451, 2019.

[7] Y. Zhu, M. K. Xiao, K. Lu, Z. H. Wu, and B. Tao, "A simplified thermal model and online temperature estimation method of permanent magnet synchronous motors," Applied Sciences, vol. 9, no. 15, p. 3158, 2019.

[8] W. L. Zhang, N. J. Ma, and J. Ma, "Mechanism of rock burst revealed by numerical simulation and energy calculation," Shock and Vibration, vol. 2020, pp. 1-15, 2020.
[9] Z. Q. Wang, P. Wang, and L. Shi, "Stress analysis of negative coal pillar gob-side entry and its principle of preventing rock burst," Shock and Vibration, vol. 2020, pp. 1-14, 2020.

[10] T. B. Zhao, W. Y. Guo, and Y. L. Tan, "Case histories of rock bursts under complicated geological conditions," Bulletin of Engineering Geology and the Environment, vol. 77, no. 4, 2018.

[11] J. P. Zuo, H. Q. Song, and Y. Q. Jiang, "Preliminary discussion on comprehensive research method for rock burst in coal mine based on Newton's second law," Shock and Vibration, vol. 2020, pp. 1-16, 2020.

[12] G. A. Zhu, L. M. Dou, and C. B. Wang, "Experimental study of rock burst in coal samples under overstress and true-triaxial unloading through passive velocity tomography," Safety Science, vol. 117, pp. 388-403, 2019.

[13] J. X. Fu, W. D. Song, and Y. Y. Tan, "Criterion of local energy release rate of gob instability in deep mines considering unloading stress path," International Journal of Mining Science and Technology, vol. 27, no. 6, pp. 1011-1017, 2017.

[14] B. R. Chen, X. T. Feng, Q. P. Li, R. Z. Luo, and S. J. Li, "Rock burst intensity classification based on the radiated energy with damage intensity at jinping II hydropower station, China," Rock Mechanics and Rock Engineering, vol. 48, no. 1, pp. 289-303, 2015.

[15] Y. S. Yang, S. J. Wei, and S. N. Zhao, "Research on the destructional pattern of surrounding rock of roadway induced by dynamic disturbance," Geotechnical \& Geological Engineering, vol. 37, no. 5, pp. 4447-4459, 2019.

[16] J. K. Wu, Y. Dong, and Y. Jiang, "Research on plastic zone evolution law of surrounding rock of gob-side entry retaining under typical roof conditions in deep mine," Shock and Vibration, vol. 2020, pp. 1-13, 2020.

[17] G. F. Wang, S. Y. Gong, L. M. Dou, W. Cai, X. Y. Yuan, and C. J. Fan, "Rockburst mechanism and control in coal seam with both syncline and hard strata," Safety Science, vol. 115, pp. 320-328, 2019.

[18] S. Q. He, D. Z. Song, Z. L. Li et al., "Mechanism and prevention of rockburst in steeply inclined and extremely thick coal seams for fully mechanized top-coal caving mining and under gob filling conditions," Energies, vol. 13, no. 6, p. 1362, 2020.

[19] F. Cui, S. Dong, X. P. Lai, J. Q. Chen, J. T. Cao, and P. F Shan, "Study on rule of overburden failure and rock burst hazard under repeated mining in fully mechanized top-coal caving face with hard roof," Energies, vol. 12, no. 24, p. 4780, 2019.

[20] F. Cui, T. H. Zhang, X. P Lai, J. T Cao, and P. F Shan, "Study on the evolution law of overburden breaking angle under repeated mining and the application of roof pressure relief," Energies, vol. 12, no. 23, p. 4513, 2019.

[21] P. Kong, L. S. Jiang, J. P. Jiang, Y. N. Wu, L. J. Chen, and J. G. Ning, "Numerical analysis of roadway rock-burst hazard under superposed dynamic and static loads," Energies, vol. 12, no. 19 , p. $3761,2019$.

[22] C. C. Wei, C. G. Zhang, I. Canbulat et al., "Evaluation of current coal burst control techniques and development of a coal burst management framework," Tunnelling and Underground Space Technology incorporating Trenchless Technology Research, vol. 81, pp. 129-143, 2018.

[23] W. Y. Guo, T. B. Zhao, and Y. L. Tan, "Progressive mitigation method of rock bursts under complicated geological conditions," International Journal of Rock Mechanics and Mining Sciences, vol. 96, pp. 11-22, 2017.

[24] K. P. Zhou, Y. Lin, and H. W. Deng, "Prediction of rock burst classification using cloud model with entropy weight," 
Transactions of Nonferrous Metals Society of China, vol. 26, no. 7, pp. 1995-2002, 2016.

[25] L. M. Taylor, E.-P. Chen, and J. S. Kuszmaul, "Microcrackinduced damage accumulation in brittle rock under dynamic loading," Computer Methods in Applied Mechanics and Engineering, vol. 55, no. 3, pp. 301-320, 1986.

[26] B. H. G. Brady and E. T. Brown, Rock Mechanics for Underground Mining, Springer, Amsterdam, Netherlands, 3rd edition, 2006.

[27] W. Cai, L. M. Dou, and G. Y. Si, “A new seismic-based strain energy methodology for coal burst forecasting in underground coal mines," International Journal of Rock Mechanics and Mining Sciences, vol. 123, Article ID 104086, 2019.

[28] H. Q. Yang, C. L Han, N. Zhang, C. L. Sun, D. J. Pan, and M. H. Dong, "Stability control of a goaf-side roadway under the mining disturbance of an adjacent coal working face in an underground mine," Sustainability, vol. 11, no. 22, p. 6398, 2019.

[29] X. W. Feng, N. Zhang, F. Xue, and Z. Z. Xie, "Practices, experience, and lessons learned based on field observations of support failures in some Chinese coal mines," International Journal of Rock Mechanics and Mining Sciences, vol. 123, Article ID 10409, 2019. 